\title{
Timing of the 8.2-kyr event in a stalagmite from Northern Oman
}

\author{
Hal Cheng $^{1,4}$, D. Fleitmann ${ }^{2}$, R.L. Edwards ${ }^{1}$, S.J. Burns ${ }^{3}$ and A. Matter ${ }^{2}$ \\ 'Department of Geology and Geophysics, University of Minnesota, Minneapolis, USA; cheng021@umn.edu \\ 2Institute of Geological Sciences, University of Bern, Switzerland. \\ ${ }^{3}$ Department of Geosciences, University of Massachusetts, Amherst, USA \\ ${ }^{4}$ College of Geography Science, Nanjing Normal University, China
}

The 8.2-kyr event (Alley et al., 1997) is the most outstanding Holocene cooling episode in Greenland ice cores. This distinct event was triggered by a large outburst of meltwater from glacial Lake Agassiz through the Hudson strait into the North Atlantic at around $8.470 \pm 0.300 \mathrm{kyr}$ BP (Barber et al., 1999). The resultant freshening of the North Atlantic led to a weakening of the thermohaline circulation and widespread cooling in the North Atlantic regions (Alley and Ágústsdóttir, 2005). Furthermore, low levels of atmospheric methane indicate a drying of the tropics (Alley et al., 1997).

However, in many paleoclimate time series, unambiguous identification of the 8.2-kyr cold event is hindered by considerable age uncertainties and low temporal resolution. Furthermore, this event seems to be superimposed on a longer-term cold and dry period that lasted from around 8.6 to 8 kyr BP (Rohling et al., 2005). As a result, climatic anomalies occurring at approx. $8.2 \mathrm{kyr}$ BP have often been wrongly ascribed to the 8.2-kyr event (Rohling et al., 2005).

Overall, the timing and geographical extent of this event are still a matter of debate, as precisely dated paleoclimate records are rare, particularly throughout the tropics (Alley and Ágústsdóttir, 2005). Whether anomalies around 8.2 kyr BP observed in paleoclimate archives are really representative of one synchronous event, different events or a one-time transgressive event remains largely unanswered. In order to resolve this puzzle surrounding the 8.2-kyr event, precise dating becomes critical. Stalagmites have the potential to contribute high-quality time series due to their precise and absolute chronologies. Here, we present a precisely-dated stalagmite from N. Oman to document the response of the Indian summer monsoon to the 8.2-kyr event in great detail.

\section{Stalagmite $\mathrm{H} 14$}

Stalagmite H14 (Fig. 1a) was collected from Hoti Cave in N. Oman $\left(23^{\circ} 05^{\prime} \mathrm{N}, 57^{\circ} 21^{\prime} \mathrm{E}\right)$. Present-day climate in this area is arid and most of the total annual rainfall occurs during winter and spring, and limited rainfall occurs during summer by local thunderstorms (Fleitmann et al., 2007). During the early- to mid-Holocene, however, N. Oman was under the direct influence of the Indian summer monsoon and most of the annual precipitation occurred during summer (Burns et al., 1998; Fleitmann et al., 2003a). High monsoon precipitation is indicated by abundant early- to mid-Holocene stalagmites, whereas today, only a few and comparably small stalagmites are actively growing.

Stalagmite $\mathrm{H} 14$ shows well-developed annual bands over its entire length. Their thickness varies between 0.1 and $0.6 \mathrm{~mm}$ around a mean of $0.3 \mathrm{~mm}$. The chronology of $\mathrm{H} 14$ is based on new ${ }^{230} \mathrm{Th}$ dating techniques, which allowed us to obtain $15{ }^{230} \mathrm{Th}$ dates with unprecedented

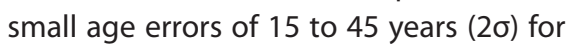
the interval between 7.65 and $8.6 \mathrm{kyr}$ BP (Fig. 1b). Precise ${ }^{230} \mathrm{Th}$ dating is also facilitated by high uranium contents of $\sim 1.5$ ppm and very low detrital contamination ${ }^{230} \mathrm{Th} /{ }^{232} \mathrm{Th}$ atomic ratios are well above 1000). All ${ }^{230} \mathrm{Th}$ ages are in stratigraphic order, within the age uncertainties, and in very good agreement with annual band counts (Fig. 1b). This indicates that the observed sub-mm bands are indeed annual. The combination of accurate ${ }^{230} \mathrm{Th}$ dates and annual band counts allow us to construct a precise age model that is far more

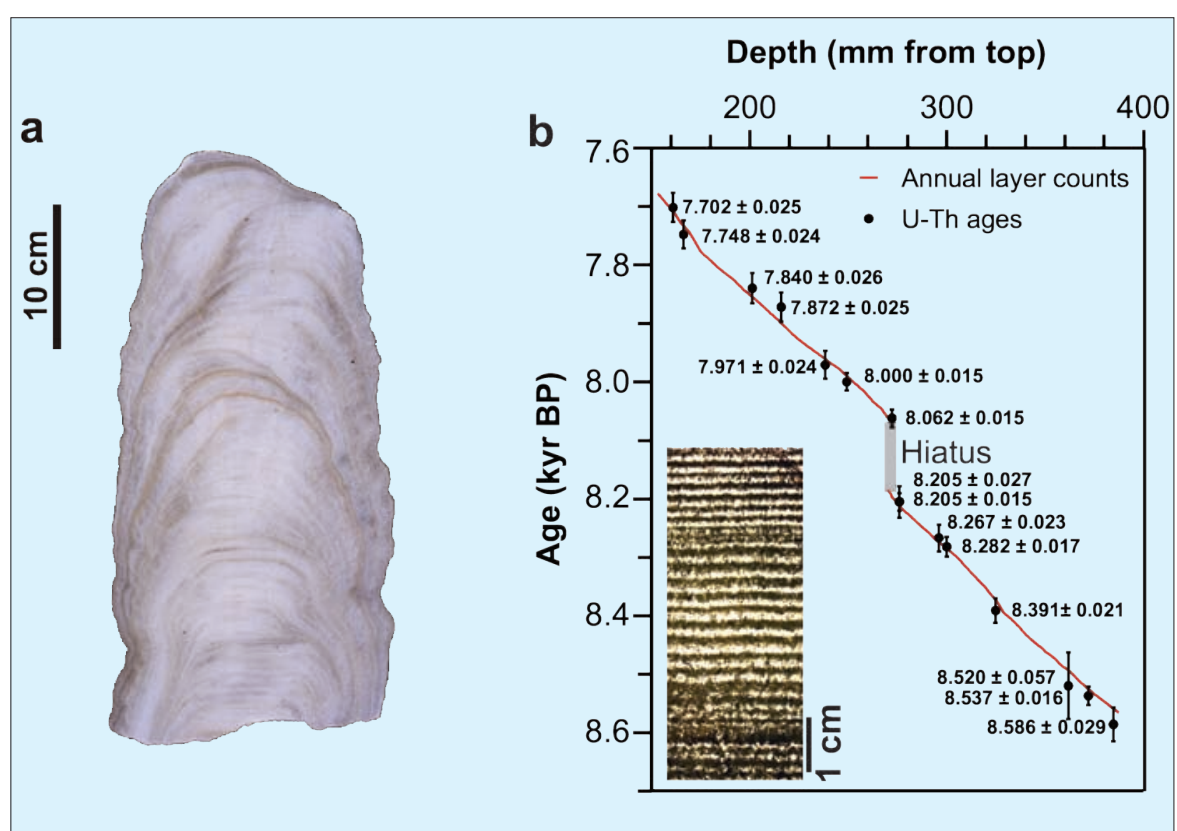

Figure 1: $\boldsymbol{a}$ ) Image of stalagmite H14 from Northern Oman; $\boldsymbol{b})$ Depth versus age plot for Stalagmite H14. Black dots with error bars denote ${ }^{230}$ Th dates, red line shows annual band counts. Small inserted image shows well-developed annual bands, which are couplets of a dense (white) and more porous (black) calcite layers. individual ${ }^{230}$ Th dates. precise than linear interpolation between

A total of 388 oxygen isotope $\left(\delta^{18} \mathrm{O}\right)$ measurements were made at an average temporal resolution of 2 years. Previous studies have shown that variations in $\delta^{18} \mathrm{O}$ in early- to mid-Holocene stalagmites from Oman are primarily driven by changes in the amount of monsoon precipitation (Fleitmann et al., 2003; 2004), with more negative $\delta^{18} \mathrm{O}$ values being associated with higher precipitation and vice versa (so-called "amount effect"). This assumption is supported by the good agreement between $\delta^{18} \mathrm{O}$ and annual band thickness (ABT). Thicker (thinner) annual bands, indicative of greater drip-water supply at times of enhanced precipitation, coincide with more negative (positive) $\delta^{18} \mathrm{O}$ values (Fig. 2).

\section{Timing of the 8.2-kyr event}

The depth versus age plot (Fig. 1b) indicates an interruption in stalagmite deposition at $8.193 \pm 0.015 \mathrm{kyr}$ BP (age error was taken from the closest ${ }^{230} \mathrm{Th}$ date at 8.205 $\pm 0.015 \mathrm{kyr}$ BP) as a result of a cessation in drip water supply, due to a significant drop in monsoon precipitation. The most likely cause for the reduction in monsoon precipitation is that strong winter cooling and enhanced Eurasian snow cover weak- 

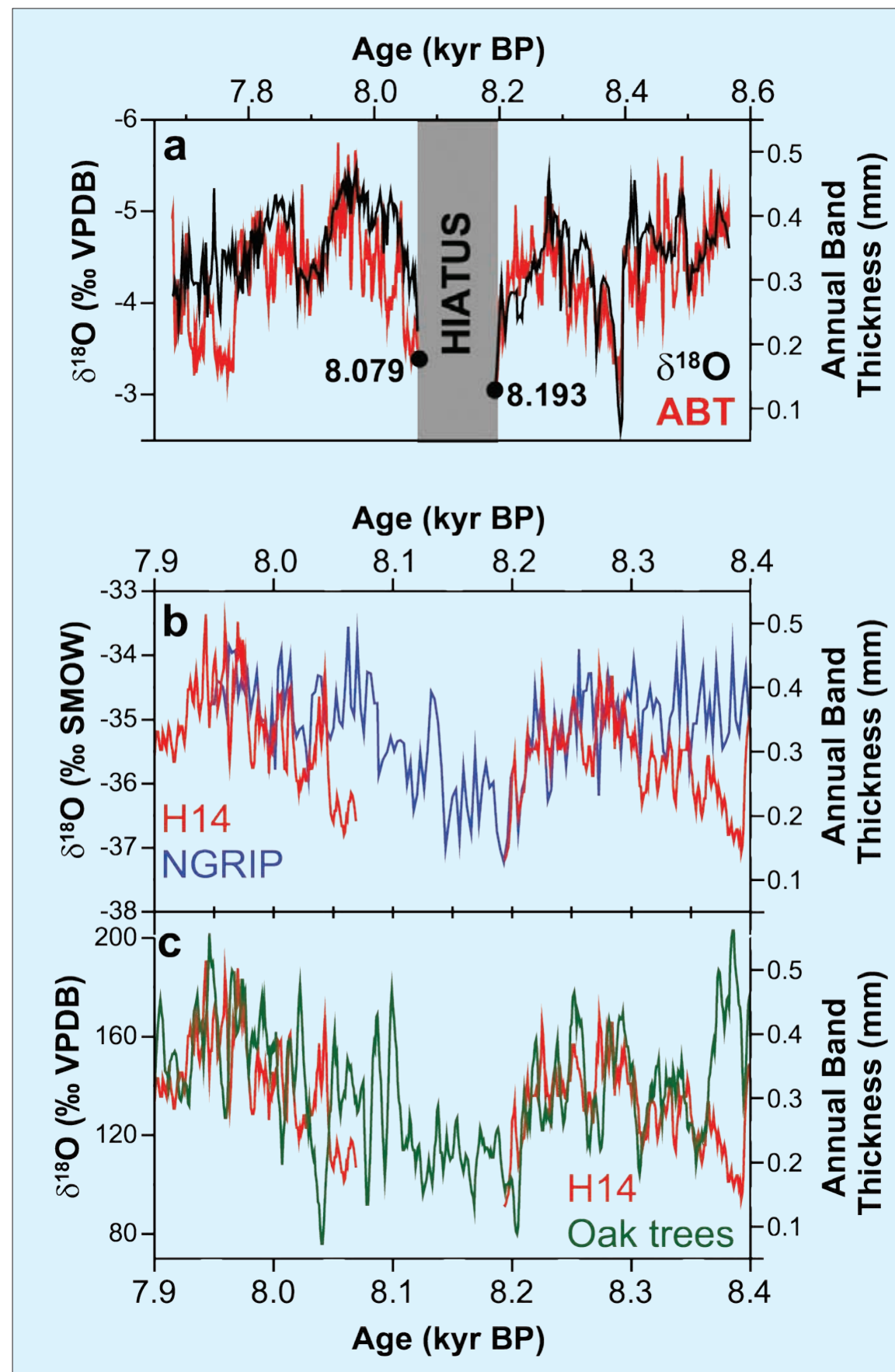

Figure 2: a) Comparison between $\delta^{18} \mathrm{O}$ and annual band thickness (ABT) in stalagmite H14; $\boldsymbol{b}$ ) Comparison between stalagmite H14 ABT profile and NGRIP $\delta^{18} \mathrm{O}$ profile (Rasmussen et al., 2006); c) Comparison between stalagmite H14 ABT profile and German oak tree-ring chronology (Spurk et al., 2002).

ened monsoon circulation by reducing the land-sea thermal contrast that drives the Indian summer monsoon (e.g., Fleitmann et al., 2003b, 2007). The timing of the decline in monsoon precipitation in N. Oman is in excellent agreement with the rapid temperature drop of approximately $5-8^{\circ} \mathrm{C}$ at $8.210 \pm 0.047 \mathrm{kyr} B \mathrm{BP}$ (based on the most recent GICC05 chronology, Rasmussen et al., 2006) in ice cores from Greenland. Additionally, the annually-precise German oak tree-ring record shows that a shift towards cooler and drier climatic conditions occurs at 8.204 kyr BP (Spurk et al., 2002). This date is in good agreement with the abrupt positive shift in $\delta^{18} \mathrm{O}$ and decrease in $A B T$ in stalagmite $\mathrm{H} 14$ from Oman at around $8.202 \pm 0.016$ kyr BP (Fig. 2C). Fur- ther support derives from other precisely dated stalagmites from Dongge Cave (China) and Padre Cave (Brasil), which place the onset of the $8.2 \mathrm{kyr}$ event at $8.230 \pm$ 0.025 and $8.203 \pm 0.015 \mathrm{kyr} \mathrm{BP}$, respectively (Cheng et al., in prep.). The independently ${ }^{230} \mathrm{Th}$ dated stalagmite $\mathrm{H} 14$ thus confirms the most recent ice core (GICC05 timescale) and oak tree-ring chronologies, and suggests that the 8.2-kyr event is indeed synchronous across the northern hemisphere. We note that the mean calibrated ${ }^{14} \mathrm{C}$ age of $8.470 \pm 0.300 \mathrm{kyr}$ BP for the catastrophic meltwater outburst from Lakes Agassiz and Ojibway (Barber et al., 1999) is somewhat older but this offset can be explained by sediment mixing and considerable uncertainties in local marine res- ervoir age estimates in the Hudson Strait (Teller and Leverington, 2004). Providing a precise estimate for the duration of the 8.2-kyr cold event is somewhat difficult as its termination seems to be rather gradual. Nevertheless, the hiatus in stalagmite $\mathrm{H} 14$ lasted from $8.193 \pm 0.015$ to $8.079 \pm 0.015$ kyr BP, similar to the duration recorded in ice cores from Greenland (Fig. 2b).

\section{Conclusion}

Our results suggest a commencing date for the 8.2-kyr event of around $8.202 \pm$ 0.015 kyr BP in N. Oman, which is in good agreement with dates provided by Greenland ice cores and German oak tree-ring record. The 8.2-kyr event thus occurred synchronously within the dating errors, revealing the hemispheric extent and atmospheric transmission of the event from the North Atlantic to the tropics. This example from Oman demonstrates that an important strength of stalagmite-based paleoclimate reconstructions is their superior chronology, which enables identification of abrupt climatic events with very high precision.

\section{References}

Alley, R.B., Mayewski, P.A., Sowers, T., Stuiver, M., Taylor, K.C. and Clark, P.U., 1997: Holocene climatic instability: A prominent, widespread event 8200 yr ago, Geology, 25: 483-486.

Alley, R.B. and Agustsdottir, A.M., 2005: The 8k event: cause and consequences of a major Holocene abrupt climate change, Quaternary Science Reviews, 24: 1123-1149.

Fleitmann, D. et al., 2007: Holocene ITCZ and Indian monsoon dynamics recorded in stalagmites from Oman and Yemen (Socotra), Quaternary Science Reviews, 26: 170-188.

Rasmussen, S.0. et al., 2006: A new Greenland ice core chronology for the last glacial termination, Journal of Geophysical ResearchAtmospheres, 111, D06102, doi: 10.1029/2005JD006079.

Spurk, M., Leuschner, H.H., Baillie, M.G.L., Briffa, K.R. and Friedrich, M., 2002: Depositional frequency of German subfossil oaks: climatically and non-climatically induced fluctuations in the Holocene, Holocene, 12(6): 707-715.

For full references please consult:

www.pages-igbp.org/products/newsletters/ref2008_3.html 